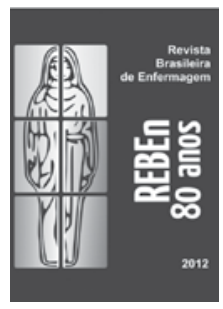

\title{
O clássico e o emergente: desafios da produção, da divulgação e da utilização do conhecimento da Enfermagem
}

The classical and the emerging: challenges in the production, dissemination and use of Nursing knowledge El clásico y el emergente: desafíos de la producción, de la divulgación y de la utilización del conocimiento de la Enfermería

\author{
Márcia de Assunção Ferreira' \\ I Universidade Federal do Rio de Janeiro, Escola de Enfermagem Anna Nery, \\ Departamento de Enfermagem Fundamental. Rio de Janeiro-RJ, Brasil.
}

Submissão: 08-07-2013 Aprovação: 08-07-2013

\section{RESUMO}

Reflexão sobre os paradigmas da ciência e os desafios contemporâneos da produção, divulgação e utilização do conhecimento. Abordam-se os desafios relativos à pesquisa do cuidado de enfermagem, os recursos e as estratégias políticas da área para superálos. Os argumentos se amparam na Enfermagem como disciplina prática e na tríade ensinar-cuidar-pesquisar voltada às demandas dos usuários, com vistas à promoção da saúde e bem-estar, dentro de um paradigma de cuidado. Articular os modelos de ciência, ampliar os recursos humanos, materiais e financeiros, investir nos mestrados profissionais, na ampliação dos programas de pósgraduação acadêmicos e na formação de redes de cooperação são alguns dos desafios e estratégias apontados para que a área enfrente as lutas do campo hegemônico da saúde, da ciência e da tecnologia para se manter no sistema.

Descritores: Ciência; Conhecimento; Enfermagem; Pesquisa.

\section{ABSTRACT}

This is a reflection about the paradigms of science and the contemporary challenges deriving from knowledge production, dissemination and use. The challenges are addressed with regard to research on nursing care, resources and political strategies in the area to overcome them. The arguments rest on nursing as a practical discipline and on the triad teaching-care-research, focused on users' demands, with a view to the promotion of health and wellbeing, within a care paradigm. Articulating the science models, expanding human, material and financial resources, investing in professional master's programs, in the expansion of academic graduate programs and in the formation of cooperation networks are some of the challenges and strategies indicated for the area to face the struggles in the hegemonic area of health, science and technology, so as to continue in the system.

Key words: Science; Knowledge; Nursing; Research.

\section{RESUMEN}

Esta es una reflexión sobre los paradigmas de la ciencia y los desafíos contemporáneos de la producción, divulgación y utilización del conocimiento. Se abordan los desafíos relativos a la investigación de la atención de enfermería, los recursos y las estrategias políticas del área para superarlos. Los argumentos se amparan en la enfermería como disciplina práctica y en la tríade enseñar-cuidar-investigar orientadas para las demandas de los usuarios con vistas a la promoción de la salud y bienestar, dentro de un paradigma de atención. Articular los modelos de la ciencia, ampliar los recursos humanos, materiales y financieros, investir en cursos de maestría profesional, en la ampliación de los programas académicos de post grado y en la formación de redes de cooperación son algunos de los desafíos y estrategias apuntados para que el área enfrente las luchas del campo hegemónico de la salud, de la ciencia y de la tecnología para mantenerse en el sistema.

Palabras clave: Ciencia; Conocimiento; Enfermería; Investigación.

\section{AUTOR CORRESPONDENTEＭárcia de Assunção Ferreira E-mail: marciadeaf@ibest.com.br}




\section{EXPLICAÇÕES PRELIMINARES SOBRE AS APROXIMA- ÇÕES AO TEMA}

Este texto reúne conteúdos oriundos da experiência de alguns anos dedicados ao trabalho de ensinar-cuidar-pesquisar na enfermagem, tríade evocada pela ilustre professora Vilma de Carvalho, Professora Emérita da Universidade Federal do Rio de Janeiro, em artigo de sua autoria no qual afirma que “o quanto mais e melhor aprende-se a cuidar é cuidando (...). Como professora, só entendo o processo de ensinar no plano pedagógico do engajamento com as situações da prática assistencial"(1). Dissertando sobre a Enfermagem e seu projeto pedagógico-epistemológico, prossegue em defesa de que "os problemas mais condizentes com as pesquisas na enfermagem são os mesmos que interferem na esfera do cuidado aos clientes", enfatizando que "tais problemas precisam ultrapassar os interesses individuais dos pesquisadores, para compreender o mundo real das pessoas e de suas famílias"(1).

Estes trechos servem-nos de inspiração e alinham-se sobremaneira ao temário sobre o qual nos deteremos a tratar, uma vez que a finalidade que guiou a construção deste texto é a de refletir acerca da produção de conhecimento sobre o cuidado às pessoas e sua saúde, a divulgação e utilização desta produção, tendo em vista que esta tríade só faz sentido se for a favor da prática e da formação da enfermeira. Neste intento, pesquisar para melhor compreender "o mundo real das pessoas e de suas famílias"(1) com o objetivo de cuidar já é, em si, um grande desafio.

As palavras-chaves dos trechos destacados agrupam-se em dois conjuntos, a saber, a) Enfermagem, prática, ensinar-cuidando; e b) problemas de pesquisa, cuidar-cuidado, mundo real das pessoas. Vamos nos deter nelas para dialogar sobre o clássico e o emergente na ciência, e o que estes paradigmas nos trazem como grade de leitura para elucidar as muitas questões que envolvem a produção, a difusão e aplicação do conhecimento sobre o cuidado, objeto de conhecimento e prática da enfermagem.

A produção deste texto também está situada no lugar que ora ocupo no plano do ensino-pesquisa e formação de enfermeiras: que é o da Enfermagem e seus fundamentos. Portanto, as pesquisas que desenvolvo no âmbito do grupo de pesquisa que lidero tratam, substancialmente, do estudo do cuidado e de uma clínica que comporta tanto a dimensão material, objetivada em técnicas procedimentais, quanto a singeleza expressiva do cuidado que dá o tom das muitas maneiras/estilos de cuidar de enfermeiras, que transcendem os protocolos de ações pré-concebidas, mas se faz/se (re)construindo nas representações e no cotidiano de práticas de saúde.

Os desafios, que estão aqui priorizados neste texto tiveram a vista de um ponto: o da Enfermagem na sua dimensão ciência e arte de cuidar de pessoas.

\section{O QUE, POR QUE, PARA QUE, PARA QUEM PRODUZIR E COMO PESQUISAR?}

Desafios situados no objeto e na finalidade do conhecimento

Em grande parte, os desafios que se colocam no campo da ciência, e da pesquisa em Enfermagem, foco do momento, se situam nas questões que envolvem os modelos de abordagem do objeto, a justificativa e a finalidade da investigação, as aplicações do conhecimento que se produziu. No esforço tentativo de respondê-las, há que se pensar que a pesquisa em Enfermagem, situada na contemporaneidade, nos conduz a refletir sobre sua trajetória neste campo, no curso dos acontecimentos que a conduziu ao lugar que ora ocupa no desenvolvimento da ciência, seu status no campo científico, como a enfermagem está se organizando na produção científica, o que está sendo feito com os produtos de suas pesquisas, os resultados de suas aplicações, que impactos sociais está causando, enfim, nos remete a refletir sobre os muitos desafios enfrentados ao longo destes 150 anos, desde a fundação da enfermagem moderna, por Florence Nigthingale.

\section{A pesquisa do cuidado de enfermagem}

A palavra ciência vem do latim e significa conhecimento, mas, apesar deste ser tomado como sinônimo de ciência, nem todo conhecimento é ciência. O conhecimento científico é um entre outros possíveis ${ }^{(2)}$.

Ciência se define por um sistema de aquisição de conhecimento, sistemático e metódico, corpo de conhecimentos organizados, fruto da aplicação de método científico - através da pesquisa. Pesquisa científica é, portanto, um processo sistemático de construção do conhecimento, cuja finalidade é: gerar novos conhecimentos, reafirmar ou refutar os já existentes. A opção por aludir à reconstrução do conhecimento e não a sua construção é em defesa de que se parte, sempre, de algo que já se sabe sobre o objeto investigado(2).

(Re)construir conhecimento é, portanto, pesquisar e elaborar algo em torno de um objeto/fenômeno de modo que se tenha outras visões sobre "o mesmo" e se abram outros e mais canais de exploração, e se apontem outros e mais caminhos a seguir na trajetória desta (re)construção.

A pesquisa é, por conseguinte, parte importante deste processo sistemático que se traduz no método científico, o qual define o conjunto de regras básicas que serão aplicadas na condução da (re)construção do conhecimento. Ora, se ciência se faz com teoria e método, não há possibilidade de fazê-la sem articulá-los. Este diálogo será sempre necessário.

Neste intento, a Enfermagem vem investindo na descoberta da essência dos fenômenos de seu interesse, transpassando as aparências para entender seu objeto e suas práticas. Tem nos metaparadigmas um caminho para o delineamento de um conhecimento específico que assegure à Enfermagem seu lugar no campo da ciência: A natureza da Enfermagem (a ciência e a arte da disciplina); a Pessoa (indivíduo, família, comunidade, humanidade); a Sociedade e o Meio Ambiente (os arredores imediatos, a comunidade ou o universo); a Saúde (estado de bem estar decidido entre a enfermeira e o usuário) $)^{(3-4)}$.

Produzir conhecimento na Enfermagem requer esforço de articulação e diálogo entre os metaparadigmas que nos dão identidade e os paradigmas da ciência que coexistem na contemporaneidade. O clássico e o emergente que, em separado ou em comunhão, permitem dar as explicações necessárias à ultrapassagem da aparência dos fenômenos.

O clássico conduz a produção de conhecimento sobre o objeto com foco nas características objetivas observáveis, e 
o emergente o faz objetivando e valorizando as subjetividades, pelo processo da observação e da conversação. Ambos os modelos são aplicáveis e necessários no fazer científico da sociedade contemporânea, para atender às múltiplas faces de problemas que se colocam, advindos do mundo real das pessoas, mormente no campo da saúde e da enfermagem.

Se tomarmos o conhecimento como resultante de uma dialética entre o sujeito epistêmico e o fenômeno sob estudo, veremos que os modelos de abordagem não se opõem, mas se complementam, debate este já posto no campo das metodologias $^{(5)}$. O desafio, portanto, é estreitar o diálogo entre os paradigmas, estabelecer a dialogicidade necessária ao bem comum de ambas, fazer os caminhos se cruzarem. Quem faz os caminhos são as pessoas, pois trilhas são traçadas pelas pegadas e ações do ser humano quando se sabe aonde se quer chegar. Se na esfera da prática da enfermagem o ponto de chegada é o bem-estar humano, pensemos nos elementos centrais que o sustentam, nas melhores trilhas e abordagens para nele chegar.

O clássico na ciência contribuiu para definir os limites das disciplinas, mas tais "limites do conhecimento disciplinar se fazem sentir especialmente quando os problemas a resolver envolvem objetos complexos", tais como a saúde e o cuidado, "e quando a redução da complexidade impede o desvelamento e a solução do problema"(6).

O cuidado é um fazer humano (em ato) e um sentir humano (sentir-se cuidado). Portanto, para investigá-lo, não basta acessar as realidades externas, é preciso compreendê-lo, investigar os múltiplos sentidos que a ele se atribui, na diversidade social das famílias, dos grupos, das culturas, das sociedades: no mundo real das pessoas. Gerar conhecimento prudente para uma vida decente, como defende Santos ${ }^{(7)}$.

Retomar este debate entre os paradigmas é oportuno para mostrar a estreita relação entre teoria, método e técnicas. $\mathrm{O}$ método integra-se à teoria e dá razão às técnicas, apontando suas possibilidades e limites na abordagem do objeto ${ }^{(6)}$.

Abordar a saúde das pessoas em vista de seu bem-estar requer aplicação de referenciais que se amparem em um paradigma de cuidado, pois este clama pela sua promoção. $\mathrm{O}$ paradigma da doença, sustentando pelo modelo biomédico e explicado pelo paradigma clássico da ciência, clama pela restauração, recuperação, reabilitação da ordem orgânica-funcional do corpo, sendo demasiado estreito para se trabalhar com a proposta de estilo de vida e sociedades saudáveis.

Pensar no cuidado e no quanto este importa para o bem-estar e dignidade humana requer o entendimento de que este não é sempre à priori, mas sob demanda e, para isso, há que se colocar o outro no centro do processo e trabalhar com o que dele emana: falar-lhe e ouvi-lo. A tríade ensinar-cuidar-pesquisar exige abordagem sutil - planejada, sistematizada mas em muitas das vezes não estruturada, pois os caminhos da investigação do humano se constroem no fazer do encontro - em muitos dos casos, de modo artesanal. As subjetividades implicadas neste processo de construção são materiais objetivos que se apresentam como uma rica matéria viva nos atos de pesquisar e de cuidar, de pesquisar-cuidando, de cuidar-pesquisando que somente são capturadas quando os humanos estão em interação. Disto se depreende que o dado não esteja lá, mas pode vir a ser e estar, na dependência do encontro entre sujeito epistêmico e fenômeno/sujeito estudado.

O cuidado, tomado como objeto de conhecimento e prática da enfermagem, se configura como atos/operações que se realizam no campo de ação da disciplina pelas enfermeiras, com fins terapêuticos, de promoção/manutenção da ordem orgânica funcional do corpo, do ambiente, do conforto e bem-estar. Mas no campo da interação entre humanos (encontro da enfermeira com o usuário), os atos não são em si cuidado, mas podem estar em potência, vir-a-ser na dependência do sentir de quem o recebe/dele participa. No ato do encontro, o cuidado ganha uma conotação que se reveste de uma noção mais aproximada da noção de "atitude" (conduta), envolve afeição ${ }^{(8)}$. Ora é objetivo, ora é subjetivo e esta dança de nuances se faz no ato vivo de cuidar e requer múltiplas abordagens e múltiplos métodos, não havendo condições de possibilidades de identidade única a um ou outro paradigma. Neste entendimento, o cuidado se faz e se (re)constrói no seu próprio processo, sendo co-emergente às relações que se estabelecem entre os sujeitos no ato ${ }^{(9)}$.

Esta instabilidade que a noção de estado dá ao cuidado, no ato vivo do encontro, e esta (in)certeza de que ele esteja em ato, só pode ser abordada na emergência de sua via-de-se-fazer, mais aproximado dos fundamentos de um modelo de ciência novo, emergente (quântico).

O clássico se aplica, na caracterização do que se faz objetivamente no campo do cuidado, no estabelecimento de relações entre as causas, as intervenções e seus efeitos observáveis; e o emergente se aplica, no empenho de trazer à tona resultados traduzidos em respostas humanas às ações, em efeitos de sentidos e explicações que só o ser humano consegue (re) produzir. O clássico e o emergente, em ação e em diálogo, se interconectam em favor do cuidado e do bem-estar humano.

Este é um desafio na produção e na (re)construção do conhecimento da enfermagem porque o campo da saúde ainda vive o dilema dos paradigmas que o sustentam ${ }^{(10)}$. Se por um lado apregoa-se a promoção da saúde e do cuidado (de si e dos outros), por outro ainda é forte a linha de adoção de estratégias de ação que se amparam na prevenção de doenças e no modelo biomédico de abordagem do corpo e de suas reações.

Os elementos que conformam tais paradigmas circulam nas conversações através de todos os tipos de mídia, dos discursos profissionais, nas relações sociais. Apesar de haver esta circulação de saberes, no campo da saúde pública ainda há hegemonia do paradigma biomédico, centrado nos diagnósticos e nas medidas curativas. A despeito disso, apesar de o modelo preventivo e o de promoção da saúde enfatizarem o cuidado, há que se considerar que o paradigma que tem grande potencial para conduzir o sujeito ao cuidado de si e as sociedades em modos de ser saudáveis é o da promoção da saúde.

A promoção da saúde pode ser identificada como um conjunto de estratégias "que envolve um campo de conhecimentos e práticas transversais a todas as ações e níveis de atenção em saúde"(11). Não seria, portanto, um nível de atenção e nem estaria situada em fase anterior ao da prevenção, mas umbilicalmente aproximada da qualidade de vida e não do controle de enfermidades ${ }^{(11)}$. 
Disto decorre que, à luz deste paradigma, as pessoas precisam estar presentes no processo de cuidado, participativas, criando e recriando modos de pensar e agir em prol de sua saúde. Este modelo de abordagem exige participação social, consciência cidadã, reflexão e ação. E é neste ínterim que a pesquisa do cuidado se faz, ou deve se fazer: no ato de se estar cuidando-ensinando-pesquisando. O emergente assim toma vulto de modo a se fazer fluir o conhecimento a partir do "mundo real das pessoas e das famílias"(1), exigindo uma filosofia e uma epistemologia que lhe seja apropriada.

Daí se deriva um desafio, que é o de se ter e sustentar uma identidade própria nos modos de se fazer ciência, (re) criar métodos de pesquisa alinhados ao novo paradigma, nos impondo no campo científico. As expressões-chave são: fazer com, pesquisar com, ensinar com, cuidar com, pois se de acordo com o que estamos aqui defendendo, o cuidado é sempre uma construção coletiva, a produção de conhecimento sobre este objeto também o deve ser.

A Ciência da Enfermagem, em seu processo de construção, vem se deparando com inúmeros desafios que se impõem ao conhecimento científico: assentar-se em bases filosóficas claras e sólidas que fundamentem o conhecimento da área, para dar sustentação às suas afirmações, deter-se no objeto de sua ciência, ter claro o campo da disciplina e ver como este se relaciona com as ciências afins, ou seja, estabelecer o diálogo interdisciplinar.

A descrição do saber da Enfermagem pautada na captação da natureza específica do seu objeto e de sua finalidade contribui para delimitar seu campo específico, estabelecendo as fronteiras de sua disciplina, colocando-a em condições de debate frente às outras ciências. Marcar suas diferenças distinguindo-a de outros campos do saber, na (re)construção de um conhecimento específico que abarque a natureza dos fenômenos da enfermagem tem sido o movimento intelectual da área e o grande desafio da enfermagem na contemporaneidade. Que se soma ao trabalho de, a partir daí, estabelecer o diálogo interdisciplinar. Isto reforça a defesa de que a pesquisa, na contemporaneidade, possui papel político e estratégico na geração de conhecimentos que afirmem a ciência, na sustentação do campo da enfermagem.

A geração de conhecimento científico, mormente no campo da saúde e da Enfermagem, exige que se aplique a inteligência em prol do bem comum, que se tenha formação acadêmica adequada em que a pesquisa emerja como estratégia e procedimento de aprendizagem - princípio educativo (articulado ao ensino e a extensão); exige que se ampliem os movimentos de qualificação acadêmica - pós-graduação stricto-sensu - âmbito na qual se lança olhar crítico sobre a enfermagem (ciência e arte - prática), para que se problematizem "o mundo real das pessoas e de suas famílias"(1), se revisem, questionem, critiquem, se discutam os saberes e os fazeres da saúde.

No âmbito da pós-graduação stricto-sensu espera-se que se produzam e se (re)construam os saberes necessários à geração de teorias, métodos, tecnologias e inovações. Donde se deriva o entendimento de que os espaços de formação/qualificação (graduação e pós-graduação) são o celeiro da formação de pesquisadores e o lócus de sustentação da ciência, mas os espaços da prática são a razão de ser da disciplina. A prática é o lócus de sua aplicação e experimentação, onde será efetivamente materializado o conhecimento, no interior das práticas cotidianas do trabalho de enfermagem ${ }^{(12)}$.

Neste ínterim, vislumbra-se uma questão emergente: o movimento de incremento dos mestrados profissionais vem a ocupar lugar importante neste processo, uma vez que sua finalidade é estreitar os laços entre a academia e a prática rompendo com a dicotomia clássica do pensar e do fazer, herança da cisão cartesiana amparada no penso, logo existo. Incrementar os mestrados profissionais é um desafio que se impõe à área, na medida em que esta formação exige uma releitura da formação stricto-sensu, no sentido de que esta se volte para a pragmática dos serviços na busca de soluções para as problemáticas do cotidiano da assistência e do gerenciamento do cuidado, fazendo da concretude dos espaços de cuidar campos de pesquisa e de geração de conhecimento.

Assentar a produção em objetos próprios à enfermagem, buscar métodos apropriados para abordá-los sem que se desprezem os "saberes de experiências feitos"(13) das enfermeiras, sem que se neutralize a ação do sujeito sobre o objeto, mas o reconheça e o considere na medida exata e necessária a produção científica, no estabelecimento da aliança entre o que se faz, como se faz, o que se pensa sobre o que se faz e o que pode ser feito para se ter um resultado diferente. Mais uma vez parafraseia-se Santos, ao defendermos que devemos nos colocar contra o desperdício da experiência ${ }^{(14)}$. Usar o conhecimento que se produz nos Programas de Pós-Graduação, mudar a realidade com os resultados de nossas produções: eis o desafio.

Este debate aponta que a concretude das práticas viabiliza o trabalho coletivo, entendendo-se este coletivo não como reunião de indivíduos, mas num plano ético-político de construção de redes, pautadas num projeto dialógico ${ }^{(9)}$.

Um seminário promovido pelo Conselho Nacional de Pesquisa (CNPq), realizado em 1997, tratou dos Desafios em Ciência e Tecnologia no Brasil e, à luz destes, a recomendação foi a de que os projetos de pesquisa deveriam atender aos requisitos da interdisciplinaridade, ser abrangentes, e terem equipes trabalhando em cooperação científica promovendo o intercâmbio de tecnologias, privilegiando as redes nacionais e internacionais ${ }^{(15)}$. E lá se vão 16 anos...

Portanto, no fazer da ciência na contemporaneidade a formação de rede é uma emergência e um desafio, tanto nas práticas de saúde quanto na pesquisa. Nesta última, a rede de investigadores é um dispositivo, tanto político quanto estratégico a ser usado pela área, mas sua viabilidade se assenta na consolidação de grupos e linhas de pesquisa que invistam na geração de saber em torno de projetos integrados que permitam a interação e diálogo com outros pesquisadores, pois o processo de (re)construção do conhecimento não é linear, mas espiral, sistêmico em que cada elemento do sistema sustenta o outro e, assim, a rede se organiza, cresce e se multiplica. A estratégia da rede permite a aplicação comum de modelos, métodos e a comparação de resultados em multi campos, abrangendo uma diversidade de situações que favorecem a solidez dos resultados, dando mais segurança às afirmações. 
O dispositivo das redes tem potencial para ajudar na replicação de pesquisas e testagem de modelos, que são carências que precisam ser superadas, aliada ao fato de viabilizar que se trabalhe na enfermagem com projetos mais arrojados em termos de metodologias amparadas em sólido referencial teórico $^{(16)}$ que permitam ampliar o debate na área e a intersubjetividade tão necessária nos processos de fazer ciência.

Isto faz com que a construção da informação se torne mais densa e as comunicações científicas sejam mais bem acreditadas junto aos editores, ampliando as possibilidades de difusão e consumo do conhecimento produzido, pois a difusão do conhecimento viabiliza sua aplicação, sendo ambas, fases que integram o processo de pesquisar.

\section{Recursos e estratégias políticas da área}

Ressalta-se que não se faz produção e (re)construção de conhecimento sem recursos humanos, pensados em uma política digna de contratação de pessoal para o incremento à formação de qualidade. Investimentos necessários em universidades comprometidas com o processo de formação atrelado à produção, difusão, consumo e aplicação social do conhecimento. Recursos que se voltem para a ampliação e consolidação de programas de pós-graduação stricto-sensu, com excelência nacional e internacional, geograficamente distribuídos, para fazer frente às exigências e aos desafios postos à área, bem como para a ampliação do quanti-qualitativo de enfermeiras nas equipes de assistência, para que o cuidado de enfermagem se faça enquanto tal. Recursos financeiros, os quais exigem política propositiva das universidades e agências financiadoras com editais temáticos da área da saúde, mas que atendam às demandas, realidades e emergências da área de enfermagem, que viabilizem replicar estudos sobre o objeto cuidado de enfermagem, a fim de consolidar seus resultados, testar e aplicar teorias e modelos no amparo de explicações sobre os fenômenos e os processos de cuidar.

$\mathrm{Na}$ atenção a estes desafios, a Enfermagem vem trabalhando na definição de um projeto político-científico e prioridades para a área, em debates sobre uma melhor organização e articulação política interna. Mas este também é um desafio à produção, difusão e aplicação do conhecimento, pois exige estreitamento de laços, encontros propositivos e diálogos entre as lideranças da área, mormente entre as associações científicas, especialmente a Associação Brasileira de Enfermagem (ABEn) e coordenações de área, especialmente a Coordenação de Pessoal de Ensino Superior (Capes) e o CNPq. Se uma das estratégias é se trabalhar/produzir em rede, a tessitura destes fios precisa ser feita nas oportunidades dos encontros, em discussões viabilizadas nos espaços científicos e políticos próprios da área: tanto no âmbito das universidades quanto no dos encontros nacionais. Converge para a superação dos inúmeros desafios que se impõem a área discutir com, para que se cresça junto, em respeito a um projeto político-estratégico, tecido no plano coletivo, em contextos ampliados que primam pela socialização do conhecimento e das regras do jogo político-científico.

No âmbito dos eventos realizados por estas entidades, muito se tem debatido sobre uma melhor inserção da enfermagem no campo das lutas políticas, com indicação dos desafios a serem superados, que estão tanto no âmbito micro quanto do macro poder. Deste rol, levantam-se questões sobre a necessidade de se incrementar os debates e as críticas ao que a enfermagem tem produzido, através das referências do que se tem publicado na área; a ampliação e qualificação dos periódicos científicos para que se consiga alcançar a internacionalização; a transferência do conhecimento, dando-lhe visibilidade e mostrando seu impacto social; refletir sobre a contribuição que se tem dado à construção de políticas públicas e consolidação do Sistema Único de Saúde (SUS); e a ênfase ao compromisso ético e social, próprio da prática do cientista.

Tais pontos elencados foram amplamente debatidos na Reunião da Área da Enfermagem no IV Encontro Nacional de Pós-Graduação na Área de Ciências da Saúde ${ }^{(17)}$ e têm a ver com o para que pesquisar e produzir conhecimento, pois este só faz sentido se a pesquisa cumprir seu papel social com aplicabilidade do conhecimento científico. Especialmente na enfermagem, por ser uma disciplina prática, cuja ciência aplica-se em favor do bem-estar comum: humano, ético e solidário.

\section{REFLEXÕES FINAIS}

A capacidade de atuar e de decidir das pessoas está intimamente ligada à condição que ela tem de compreender as características relevantes do contexto em que vive ${ }^{(18)}$. Portanto, importa considerar que o mundo atual está marcado pela era da ciência e da tecnologia e estes nos servem de parâmetros para que compreendamos o contexto da saúde e do cuidado às pessoas - âmbito do qual se dá a (re)construção do saber da enfermagem. A questão é: qual modelo de fazer ciência, produzir tecnologia e aplicá-la melhor condiz com os pressupostos da Enfermagem como ciência e arte?

Parafraseando Lewis Carroll, romancista e matemático britânico (1832-98), em seu livro Alice no País das Maravilhas, perguntamos: o desafio está na escolha dos caminhos ou em saber aonde se quer chegar? E agora Alice?

Retomando o início deste texto, a posição assumida é a de que os desafios a se superar na produção, difusão e uso do conhecimento têm como foco aliar o ensino, a pesquisa e o cuidado, chamado aqui de processo de ensinar-cuidar-pesquisar, para que se possa compreender "o mundo real das pessoas e de suas famílias"(1) através de caminhos (trilhas) traçados pelas pegadas e ações do ser humano na promoção da saúde e do bem-estar humano através do cuidado. Neste ínterim, se pactuamos que este seja o ponto de chegada da ciência e da arte da enfermagem, que escolhamos os melhores caminhos para nele chegar.

Este texto foi produzido em defesa do diálogo, do compartilhamento, do fazer coletivo, mas não se pretendeu firmar um discurso normativo e prescritivo de superação dos desafios em uma única direção; ao invés, se trabalhar elementos centrais que permeiam o processo complexo e multifacetado de fazer ciência, como motivação para o debate da área.

Produzir conhecimento, difundi-lo e aplicá-lo são atos humanos, fazem parte de um fazer humano, e como tal, há um princípio ético a ser considerado. Ética esta que envolve não só os modos de se fazer ciência, seus modelos e técnicas, 
mas também as relações, os acordos que se firmam entre os humanos para difundi-la, aplicá-la e para manter os grupos no campo de lutas científicas e no sistema. Nesta consideração, mais uma reflexão se impõe: a da reversão da lógica da produção e da publicação em série, fatiada e fragmentada que se alinha ao produtivismo que se instalou no campo acadêmico. Produzir, difundir, publicar e aplicar é preciso. Mas em que bases? Onde vamos chegar seguindo por este caminho?

A ética viabiliza o existir humano. Estejamos em um ou em outro paradigma [clássico, emergente] ou em ambos, em articulação e diálogo, não se pode prescindir da ética. Ética que nos faz ter respeito pela vida, numa relação intencional de vínculo com as pessoas, com as coisas, com o trabalho, com o mundo enfim. Ética que nos chama a ser solidários e que nos desperta a responsabilidade social que nos pesa quando abraçamos a causa de cuidar, de ensinar e de pesquisar, no desafio constante de buscar alternativas para superar as muitas contradições que a era da ciência e da tecnologia nos impôs: saltitar entre os sofisticados dispositivos tecnológicos que nos dão precisão nos diagnósticos, tratam e reabilitam o corpo e a existência de problemas primários de saúde que acometem grande parcela da população no mundo ${ }^{(19)}$.

Esta situação nos faz pensar que "as preocupações éticas, a responsabilidade e a liberdade tem lugar apenas enquanto alguém pode ver o outro, a si mesmo e as consequências das ações de alguém nos outros, ou em si mesmo e age de acordo com a decisão entre querer, ou não, essas consequências"(20). Neste entendimento, nós também somos os outros.

Ensinar-cuidar-pesquisar, com foco nos problemas que interferem na esfera do cuidado aos usuários, ultrapassando os interesses individuais, para compreender o mundo real das pessoas e de suas famílias, suas necessidades e demandas, além de enfrentar as lutas que se travam no campo hegemônico da saúde, da ciência e da tecnologia, mantendo-se no sistema, sendo a enfermagem uma profissão ainda jovem no campo da ciência: eis o desafio.

\section{REFERÊNCIAS}

1. Carvalho V. Cuidando, Pesquisando e Ensinando: acerca de significados e implicações na prática da enfermagem. Rev Latino-Am Enferm 2004;12(5):806-15.

2. Demo P. Metodologia do conhecimento científico. São Paulo: Atlas; 2000.

3. McEwen M, Wills EM. Bases teóricas para enfermagem. 2. Ed. Porto Alegre: Artmed; 2009.

4. Hickman JS. Introdução à teoria da enfermagem. In: George JB, organizadora. Teorias de enfermagem: os fundamentos para a prática profissional. 4. ed. Porto Alegre: Artes Médicas; 1993. p.11-20.

5. Minayo MCS, Sanches O. Quantitativo-Qualitativo: oposição ou complementaridade? Cad Saúde Pública 1993;9(3):239262.

6. Baumgarten M, Teixeira AN, Lima G. Sociedade e conhecimento: novas tecnologias e desafios para a produção de conhecimento nas Ciências Sociais. Soc Estado 2007;22(2):401-33.

7. Bachelard G. O novo espírito científico. Rio de Janeiro: Tempo Brasileiro; 2001.

8. Santos BS, organizador. Conhecimento prudente para uma vida decente. São Paulo Cortez; 2004.

9. Ferreira MA. A interação como princípio fundamental para o exercício do cuidado: contribuição conceitual para os fundamentos da enfermagem. In: $15^{\circ}$ Pesquisando em Enfermagem , $11^{\text {a }}$ Jornada Nacional de História da Enfermagem e o $8^{\circ}$ Encontro Nacional de Fundamentos. [evento na internet]. 2008 maio 12-15; Rio de Janeiro, Brasil [acesso em 08 jul 2013]. Disponível em: http://www.pesquisando.eean.ufrj. br/viewabstract.php?id $=378 \& \mathrm{cf}=2$.

10. Barros MEB, Gomes RS. Humanização do cuidado em saúde: de tecnicismos a uma ética do cuidado. Fracta Rev Psicol 2011;23(3):641-58.

11. Silva RC, Ferreira MA. Changing the perspective on specialized knowledge in nursing: an epistemological debate. Rev Latino-Am Enferm 2008;16(6):1042-1048.

12. Marcondes WB. A convergência de referencias na promoção da saúde. Saúde Soc 2004;13(1):5-13.

13. Paim L, Trentini M, Silva DGV, Jochen AA. Desafios à pesquisa em enfermagem. Esc Anna Nery Rev Enferm 2010;14(2):386-390.

14. Freire P. Pedagogia da esperança. São Paulo: Paz e Terra; 1997.

15. Santos BS. A crítica da razão indolente: contra o desperdício da experiência. 3. Ed. São Paulo: Cortez; 2001.

16. Salles EB, Barreira IA. Formação da comunidade científica de enfermagem no Brasil. Texto \& Contexto Enferm 2010;19(1):137-46.

17. Marziale MHP. Desafios da produção e divulgação do conhecimento científico da enfermagem. Acta Paul Enferm 2012;25(3):i-ii

18. Erdmann AL, Fernandes JD. Programas de pós-graduação em enfermagem no Brasil: desafios e perspectivas. Esc Anna Nery Rev Enferm 2011;15(1):7-8.

19. Esquirol JM. O respeito ou o olhar atento: uma ética para a era da ciência e da tecnologia. Belo Horizonte: Autêntica; 2008.

20. Zen AMD. A Crise de paradigmas e a ressignificação do conhecimento para o século XXI. Em Questão 2010;16(2):49-63.

21. Maturana H. Ontologia do conversar. In: Maturana H. A ontologia da realidade. Belo Horizonte: UFMG; 2001. p. 167-181. 